\title{
Modelling of Al-Cu-Mg-Fe-Ni Aluminium Alloy
}

\author{
Dhia Kadhm Suker \\ Department of Mechanical Engineering, Umm Al-Qura University, Makkah, Saudi Arabia \\ Email: dr_suker@hotmail.com
}

Received July 30, 2012; revised September 5, 2012; accepted September 15, 2012

\begin{abstract}
Hot deformation characteristics of $\mathrm{Al}-\mathrm{Cu}-\mathrm{Mg}-\mathrm{Fe}-\mathrm{Ni}$ aluminium alloy have been studied in the temperature range $350^{\circ} \mathrm{C}$ $-450^{\circ} \mathrm{C}$ and strain rate range $0.001-0.4 \mathrm{~s}^{-1}$ using hot compression tests. The experimental results were used to develop a model for predicting the material characteristics during hot deformation. A series of plane-strain compression (PSC) tests were carried out at $950^{\circ} \mathrm{C}$ and a strain rate of $0.1,1$ and $10 \mathrm{~s}^{-1}$ to several strain levels.
\end{abstract}

Keywords: Al-Cu-Mg-Fe-Ni Aluminium Alloy; Hot Deformation; Modelling

\section{Introduction}

One of the important features of the Al-Cu-Mg-Fe-Ni aluminium alloy is the heat treat ability which can change its microstructure and properties. One of the important applications for the alloy is the manufacture of aircraft engine components which utilises the high temperature treatment [1]. Whereas for domestic industry, heat treatment is also important for foraging manufactured appliances such as electric furnaces, gas furnaces, oil furnaces, induction heating furnaces, fluidized bed furnaces, and resistance heating furnaces. During manufacturing, heat treatment operations such as hot compression deformation, changes the properties of the material which can include hardening or softening using dynamic recrystallisation. Studying the behaviour of the alloy during hot deformation is important as this can help in selecting the optimal deformation conditions such that the evolution of the microstructure can be controlled hence its properties. This gives a significant value to theoretical and practical aspect in manufacturing the material.

Achieving a good model of the material requires accurate modelling of the materials behaviour during the deformation. This will help in predicting the properties of the material on a wide range of deformation conditions with higher accuracy. Extending the working conditions range requires carrying out a considerable amount of experimental research, which is a very time-consuming process. Therefore, it is desirable to develop a modelling tool to be used for prediction under extended deformation conditions with good accuracy.

In this paper a model has been developed to predict the material flow stress behaviour for $\mathrm{Al}-\mathrm{Cu}-\mathrm{Mg}-\mathrm{Fe}-\mathrm{Ni}$ aluminium alloy deformed in hot plane strain compression.
The flow curves will be described as a function of the applied variables of strain rate and deformation temperature. The model is designed to work on a wide deformation conditions such as the strain rate and the deformation temperature (adiabatic and coupled mode).

\section{Experimental Procedure}

The cast billets of $16 \mathrm{~mm}$ thick were homogenized at $500^{\circ} \mathrm{C}$ for 10 hours, then hot-rolled at $450^{\circ} \mathrm{C}$ into plates of $7 \mathrm{~mm}$ thick, and cold-rolled to $4 \mathrm{~mm}$ thick. After annealed at $450^{\circ} \mathrm{C}$ for 1 hour, the plates were fina cold-rolled into sheets of 2 and $1 \mathrm{~mm}$ in thickness. The cold reductions were $50 \%$ and $75 \%$, respectively. The specimens were annealed at different temperature (from $150^{\circ} \mathrm{C}$ to $500^{\circ} \mathrm{C}$ ) for 1 hour. It is well known that the recrystallization of aluminium alloys depends on several major factors including the amount of prior deformation and annealing time. In the current study, the recrystallization temperature was measured under the condition of deformation and a long annealing time (3600 s). The chemical composition of that alloy and the initial grain size, measured by mean linear intercepts, is given in Table 1 .

Isothermal axisymmetric compression tests using standard procedure [2] were conducted in the temperature of $350^{\circ} \mathrm{C}, 430^{\circ} \mathrm{C}, 450^{\circ} \mathrm{C}$ and $470^{\circ} \mathrm{C}$ and constant true strain rate ranging from $0.001 \mathrm{~s}^{-1}$ to $0.4 \mathrm{~s}^{-1}$ at intervals of an order of magnitude. All specimens were deformed to true strain of 0.55 and water quenched from the test temperature. The compression direction was parallel with axis of

Table 1. Chemical composition of Al-Cu-Mg-Fe-Ni alloy.

\begin{tabular}{ccccccccc}
\hline Element & $\mathrm{Al}$ & $\mathrm{Mg}$ & $\mathrm{Cu}$ & $\mathrm{Ni}$ & $\mathrm{Fe}$ & $\mathrm{Si}$ & Other & $\mathrm{d}_{0}(\mathrm{um})$ \\
\hline$\%$ & 92.49 & 2.36 & 2.33 & 1.12 & 1.04 & 0.16 & 0.50 & $60 \pm 4$ \\
\hline
\end{tabular}


the specimens. In the hot deformation tests, the system did the real-time collection of temperature, displacement, true stress, true strain and other parameters, the true stress-true strain curves obtained from the experiments are shown in Figure 1.

\section{Empirical Modelling}

Based on the experimental results shown in Figure 1, the instantaneous temperatures during deformation were calculated using a finite difference package based on the dimensions of the specimens, the deformation conditions and the heat transfer to the tools and environment. The temperature rise during deformation is shown in Figure 2 for the different deformation conditions.

The curves in Figures 1 and $\mathbf{2}$ were utilised to develop the model for the stress-strain behaviour for the range of $Z$ of $1.89 \times 10^{8}$ to $4.88 \times 10^{12} \mathrm{~s}^{-1}$ (with $Q_{d e f}=480 \mathrm{~kJ} / \mathrm{mol}$ ) based on the initial flow stress $\left(\sigma_{o}\right)$, the stresses at a strain of $0.1\left(\sigma_{0.1}\right)$, the steady state stress expected for work hardening and dynamic recovery only $\left(\sigma_{s s(e)}\right)$ the steady state stresses when dynamic recrystallisation takes place $\left(\sigma_{s s}\right)$. These stresses were read directly from the curves and were plotted against the logarithm of the Zener Hollomon parameter

$$
Z=\dot{\varepsilon} \exp \left(\frac{Q}{R T}\right)
$$

where $R$ is the gas constant $(R=8.31 \mathrm{~J} / \mathrm{mol} \mathrm{K})$

$T$ is the temperature is Kelvin

$Q$ is the activation energy $(Q=480 \mathrm{~kJ} / \mathrm{mol})$

The temperature is the actual value for the strain of interest, which gives the instantaneous values of $Z$ shown in Figure 3. Over the whole range of $Z$, the curves in Figure 3 were fitted by the following general equation.

$$
\sigma=\frac{\sinh ^{-1}(Z / A)^{(1 / n)}}{\alpha}
$$

where $n, A$ and $\alpha$ are constants obtained from the optimised curves, to give the values summarized by the following equations:

$$
\begin{gathered}
\sigma_{0}=\frac{\sinh ^{-1}(Z / 1.0 E 8)^{(1 / 6.62)}}{0.1689} \\
\sigma_{0.1}=\frac{\sinh ^{-1}(Z / 1.0 E 18)^{(1 / 2.59)}}{0.0496} \\
\sigma_{s s(e)}=\frac{\sinh ^{-1}(Z / 1.0 E 8)^{(1 / 1.36)}}{0.0677} \\
\sigma_{s s}=\frac{\sinh ^{-1}(Z / 1.0 E 8)^{(1 / 1.62)}}{0.0676}
\end{gathered}
$$

It was assumed that these equations are mechanical equations of state, so that the stress-strain curves ex- pected for isothermal deformation (i.e. constant $Z$ ) conditions could be calculated and fitted to the equation

$$
\sigma^{\prime}=\sigma_{0}+\left(\sigma_{s s(e)}-\sigma_{0}\right)\left[1-\exp \left(\frac{-\varepsilon}{\varepsilon_{r}}\right)\right]
$$

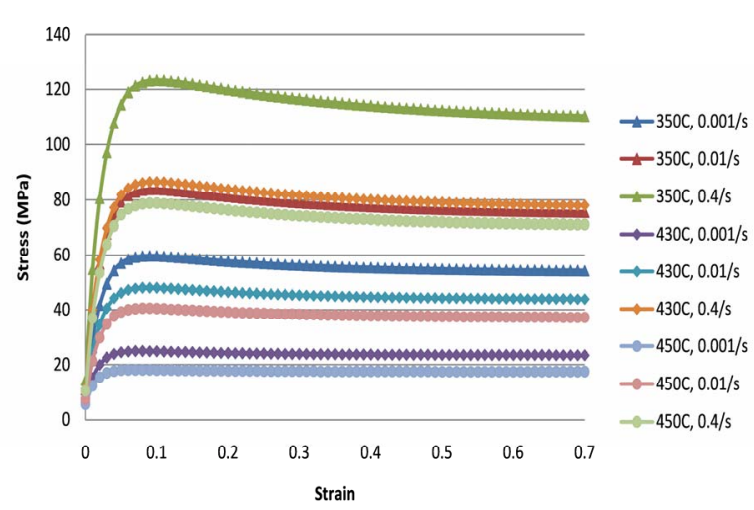

Figure 1. True stress true strain curves of $\mathrm{Al}-\mathrm{Cu}-\mathrm{Mg}-\mathrm{Fe}-\mathrm{Ni}$ aluminium alloy at different deformation conditions.

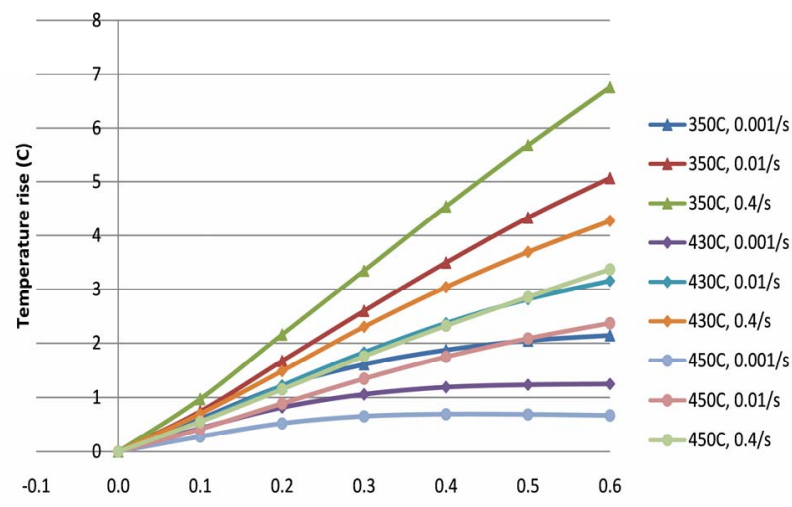

Figure 2. Calculated temperature rise due to deformational work done during PSC tests.

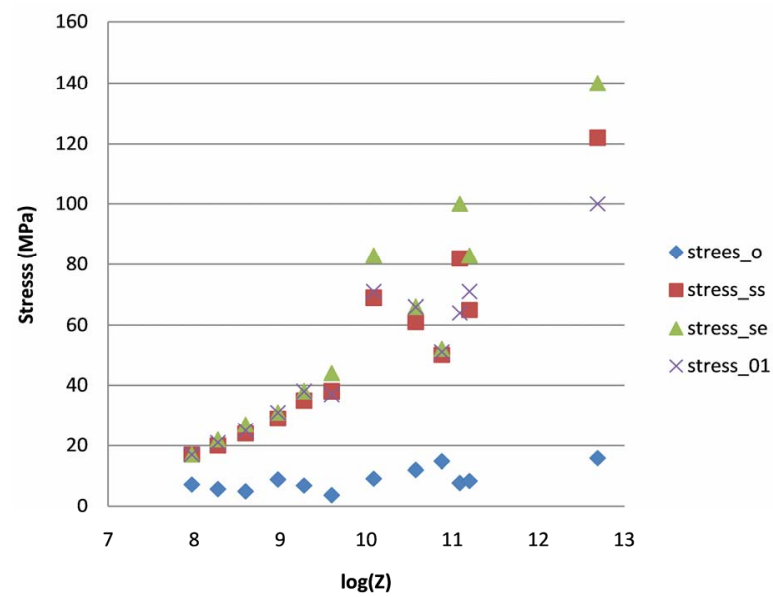

Figure 3. Measured stresses at different stains plotted gainst the logarithm of the instantaneous value of Zener Hollomon parameter. 
which applies for all strains when $\sigma_{s s(e)}=\sigma_{s s}$ but only for $\varepsilon \leq 0.7 \varepsilon_{p}$ when $\sigma_{s s}<\sigma_{(s s) e}$.

In the latter case

$$
\begin{array}{r}
\sigma=\sigma^{\prime}-1.0\left(\sigma_{s s(e)}-\sigma_{s s}\right)\left\{1-\exp \left[-0.3\left(\frac{\varepsilon-0.7 \varepsilon_{p}}{\varepsilon_{p}}\right)\right]\right\} \\
\left(\varepsilon \geq 0.7 \varepsilon_{p}\right)
\end{array}
$$

In Equation (7), $\varepsilon_{r}=\varepsilon_{s s(e)} / 2.3$ [3], where $\varepsilon_{s s(e)}$ is defined as the strain at which $\left(\sigma-\sigma_{\mathrm{o}}\right)=0.95\left(\sigma_{s s(e)}-\sigma_{0}\right)$ under isothermal conditions. In Equation (8), $\varepsilon_{p}$ is the strain at the peak stress when $\sigma_{s s}<\sigma_{(s s) e}$ under isothermal conditions. From optimised fits to these equations

$$
\varepsilon_{s s(e)}=0.8 Z^{0.1424}
$$

and

$$
\varepsilon_{p}=0.01488 \times 10^{-5} Z^{0.0612}
$$

The stress-strain curves computed for isothemal conditions are shown in Figure 4. It should be noted that the stress scale in this figure has been changed because of the major effect of the temperature rise on the experimental curves. It is noteworthy that the optimised values of $\varepsilon_{s s(e)}$ and $\varepsilon_{p}$ cross over as the value of $Z$ increases.

PSC experimental work has shown that the distribution of the strain and strain rate are heterogeneous [4]. Locally, the strain rate and accumulated strain will be different from the nominal strain which can be calculated from the changes to the specimen geometry. Consequently, the equivalent nominal stress and the equivalent strain will be dependent on the initial specimen geometry as well as on the material properties. Such correction procedure has already been developed by researcher to eliminate the geometry effect [5], so that the corrected curves give constitutive equations that reflect the true

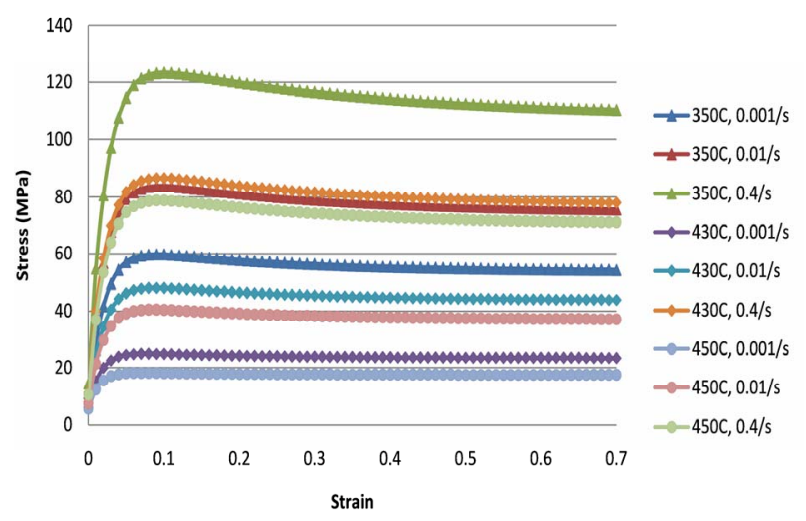

Figure 4. Stress-strain curves for isothermal conditions. material behaviour and can be applied accurately in modelling any type of hot deformation process.

\section{Conclusion}

An $\mathrm{Al}-\mathrm{Cu}-\mathrm{Mg}-\mathrm{Fe}-\mathrm{Ni}$ aluminium was deformed in planestrain compression at $350^{\circ} \mathrm{C}, 430^{\circ} \mathrm{C}$ and $450^{\circ} \mathrm{C}$ and a strain rate of $0.001,0.01$ and $0.4 \mathrm{~s}^{-1}$ to several strain levels. The corresponding temperature rise due to deformation was considered when the data were analysed. The obtained data will assist in the development of an empirically-based model of the structure evolution during thermomechanical processing of similar metallic materials.

\section{Acknowledgements}

The authors acknowledge with gratitude the financial support received from UQU, Saudi Arabia.

\section{REFERENCES}

[1] M. Zhou, D. Shu, L. Li and W. Y. Zhang, "Performance Improvement of Industrial Pure Aluminum Treated by Stirring Molten Fluxes," Materials Science and Engineering, Vol. 347, No. 1-2, 2003, pp. 280-290.

[2] M. S. Loveday, G. J. Mahon, B. Roebuck, A. J. Lacey, E. J. Palmiere, C. M. Sellars and M. R. van der Winden, "Measurement of Flow Stress in Hot Plane Strain Compression Tests," Materials at High Temperatures, Vol. 23, No. 2, 2006, pp. 85-118.

doi:10.3184/096034006782739394

[3] H. Shi, A. J. McLaren, C. M. Sellars, R. Shahani and R. Bolingbroke, "Constitutive Equations for High Temperature Flow Stress of Aluminium Alloys," Materials Science and Technology, Vol. 13, No. 3, 1979, pp. 210-216. doi:10.1179/026708397790302421

[4] M. S. Mirza and C. M. Sellars, "Multipass Rolling of Aluminium Alloys: Finite Element Simulations and Microstructural Evolution," Materials Science and Technology, Vol. 17, No. 7, 2001, pp. 1133-1141. doi:10.1179/026708301101510663

[5] B. Kowalski, A. J. Lacey and C. M. Sellars, "Correction of Plane Strain Compression Data for the Effects of Inhomogeneous Deformation," Materials Science and Technology, Vol. 19, No. 11, 2003, pp. 1564-1570. doi: $10.1179 / 026708303225008130$ 